\title{
Comparative Study on Design and Functionality Requirements for Senior-friendly Furniture for Sitting
}

\author{
Beata Fabisiak, ${ }^{\mathrm{a}, *}$ Anna Jankowska, ${ }^{\mathrm{b}}$ Robert Kłos, ${ }^{\mathrm{a}}$ Joan Knudsen, ${ }^{\mathrm{c}}$ Sari Merilampi, ${ }^{\mathrm{d}}$ and \\ Elina Priedulena ${ }^{\mathrm{e}}$
}

Furniture manufacturers' response to the demographic challenge of aging nations is an important issue. The number of seniors is rising worldwide. The aging process often results in multiple health implications, including weaker mobility, decrease in muscle mass, and change in anthropometrical dimensions of the human body. Thus, the furniture offered should be adjusted to the needs of an increasing group of senior customers. To identify seniors' preferences in relation to characteristics of sitting furniture, international surveys with 627 respondents aged 60+ years were conducted in Poland, Germany, Denmark, Finland, Latvia, and Lithuania. The implementation of this data in the design process may result in creation of the market offer meeting seniors' needs. Design and functionality features were examined to provide guidance for seniorfriendly development of furniture for sitting. Among the most important findings is the clear preference of having an armchair with the high backrest reaching above the head, a chair with armrests and an upholstered backrest and seat. Furthermore, respondents paid attention to the durability of furniture, stain resistance of upholstery, and adaptation of the furniture to the user's dimensions, e.g., having influence on the height and depth of the seat before the purchase.

Keywords: Furniture for sitting; Design; Functionality; Senior-friendly; Age-generations; Baltic Sea region countries

Contact information: Poznan University of Life Sciences, Wojska Polskiego Street 38/42, 60-627 Poznan, Poland; a: Department of Furniture Design, Faculty of Forestry and Wood Technology; $b$ : Department of Economics and Economic Policy in Agribusiness, Faculty of Economics; c: Development Centre UMT, Secretariat for Lifestyle \& Design Cluster, Birk Centerpark 38, 7400 Herning, Denmark; d: Satakunta University of Applied Sciences, Faculty of Technology, Satakunnankatu 23, 28130, Pori, Finland;

e: Hanse-Parlament e.V., Blankeneser Landstrasse 7, 22587 Hamburg, Germany;

* Corresponding author: beata.fabisiak@up.poznan.pl

\section{INTRODUCTION}

Currently, much attention is paid to ensure the best possible comfort and quality of life for seniors. Design, ergonomics, safety, and functionality features of furniture used by seniors play an important part in this area of interest. This stems from the fact that the societies, especially in developed countries, are ageing at a rapid pace. In January 2019 people aged $65+$ accounted for $20.3 \%$ of the EU-27 population, with the share of people aged 80 years or more reaching 5.8\% (EC 2020a). It is interesting that the share of seniors in the EU-27 population in 2019 was 0.3 percentage points higher than a year before and 2.9 percentage points higher than the corresponding share from a decade earlier (EC 2020b). Another indicator that shows the rapid pace at which the EU population is aging is the median age. The median age is the age that divides the population in two parts of equal size, that is, there are as many persons with ages above the median as there are with 
ages below the median (WHO 2021). The median age in the EU-27 increased 2.7 years between 2009 and 2019, rising from 41.0 years to 43.7 years (EC 2020c). When a longer period is analysed, the difference is even more evident. In 2001 the median age was 38.4 years, creating the difference of 5.3 years in comparison to the value from 2019 (EC 2020a). European Commission forecasts indicate that the number of seniors in the EU will continue to increase and will reach 149.2 million in 2050, constituting $28.5 \%$ of the EU population (EC 2019). This trend is also observed outside Europe - it is estimated that by 20502 billion people in the world will be over 60 years old. Additionally, countries of the Baltic Sea region (focus of this study) are affected by those demographic changes. The Baltic Sea region is a macro region of Europe constituting of countries having shorelines along the Baltic Sea: Denmark, Estonia, Latvia, Finland, Germany, Lithuania, Poland, Russia, and Sweden. The share of seniors in the populations of the selected Baltic Sea region countries is shown in Table 1.

Table 1. The Share of Seniors in the Populations of Selected Baltic Sea Region Countries

\begin{tabular}{|c|c|c|}
\hline Country & 2016 & 2019 \\
\hline Denmark & 18.8 & 19.6 \\
\hline Finland & 20.5 & 21.8 \\
\hline Germany & 21.1 & 21.5 \\
\hline Latvia & 19.6 & 20.3 \\
\hline Lithuania & 19.0 & 19.8 \\
\hline Poland & 16.0 & 17.7 \\
\hline
\end{tabular}

Source: (EC 2020d)

Most countries have never before dealt with such a large change in the age structure of the population. Thus, it is crucial to be prepared for the observed changes and develop product offers that meet the needs of the seniors, resulting from different types of ageingrelated health and mobility issues.

Development of ageing-friendly products is an economic matter for the municipalities and governments. It is also an ethical choice for the societies taking care of seniors. Additionally, for the private sector, such as ageing-friendly designers and product developers, it is a growing business opportunity. However, most importantly, ageingfriendly products can support the autonomy of the seniors. There is an important trend to support seniors to live independently at home as long as possible, instead of placing them in institutions and care homes. This further underlines the need for finding new ways of supporting the seniors in daily living and in maintaining their functional capabilities. Properly designed furniture may offer part of this support, whereas poor designing may even cause safety hazards. Therefore, particularly important is the set of features enhancing the functionality of furniture understood as the adjustment of the product to mental and physical characteristics of the user.

Furniture for sitting constitutes an important part of everyday lives playing a significant role both in private and public spaces. One must not forget that furniture pieces for sitting are among the pieces of furniture that are used directly - the user's body has direct contact with the furniture. Therefore, they are of crucial importance to assure comfort, safety, and quality of living.

In systematic review conducted from research in seven different countries, Harvey et al. (2013) found the majority of older adults are sedentary. Almost $60 \%$ of older adults 
reported sitting for more than $4 \mathrm{~h}$ per day, $65 \%$ sit in front of a screen for more than $3 \mathrm{~h}$ daily and over $55 \%$ report watching more than $2 \mathrm{~h}$ of TV. However, when measured objectively in a small survey, it was found that $67 \%$ of the older population were sedentary for more than $8.5 \mathrm{~h}$ daily. A Brazilian study by Meneguci et al. (2015) found the median value for sitting time to be 240 min a day. Participants were predominantly between 60 and 69 years old, educated, and physically active. Another study by Harvey et al. (2015) suggests much longer sitting times. According to the study, older adults are one of the most sedentary age groups, spending more than $60 \%$ ( 8.5 to $9.6 \mathrm{~h}$ ) of their waking day sitting (Harvey et al. 2015). Study by Leask et al. (2015) suggested that older adults often sit most in the afternoon and evening (compared with the morning), and when they are alone at home.

To conclude, previous studies found seniors spending a relatively large amount of time sitting. Because generally considerable time spent sitting negatively affects health, it is important to support seniors to do other kinds of activities. Another important aim is to design chairs that would make sitting less unhealthy and supporting daily living, as the avoidance of sitting is not always realistic. This was the primary motivation for this study, which focuses on research of the older adults' preferences related to chairs and other furniture used for sitting. In order to understand older adults' needs and preferences, it is important to study which activities are performed sitting.

Palmer et al. (2019) studied sitting activities of seniors in Scotland. Most sitting activities belonged to the leisure-time domain, with many taking place at home. Watching TV was reported by all but one person, although time spent doing this varied a lot. Other home-based sitting activities included reading, doing puzzles, crosswords, or playing games, using computers or tablets, relaxing, playing an instrument, making phone calls, listening to music/radio/books, sitting in the garden, knitting, napping, thinking, sorting medication, smoking, doing paperwork, eating, and drinking, to name some. Outside the home, sitting activities included driving/traveling, sitting in parks, theaters, cafés, pubs and restaurants, learning (poetry and computer classes), as well as playing bingo, cards, and board games. These findings offer viewpoints to interpret the results of this study. However, there may be cultural differences between countries. In this study, the cultural aspect is also taken into account by comparing the answers of older adults in different countries.

The importance of well-designed chairs is emphasised by Tinietti et al. (1994), Gill et al. (1999), and Colombo et al. (1998). Different chairs designed in the right way and used in bedrooms can be used to facilitate transfer to the bed. They may also be a good support while getting dressed. The issue of the design of chairs adapted to the needs of the seniors was raised also by Šimek (2013). In his work he drew attention to the necessity of placing the seat of the chair at a greater height, implementing armrests, ensuring greater stability as well as removable, stain-resistant upholstery, mobility, and the possibility to install additional elements, such as a cup holder or a small table. Nevertheless, it would be also important to highlight that not only placing the seat of the chair at a greater height but rather offering adjustable solutions would be crucial here. A piece of furniture that is comfortable should be adjusted to various anthropometrical dimensions including people from the $5^{\text {th }}$ percentile (meaning those $5 \%$ of the people who have smaller anthropometric dimensions than average dimensions of a given population). A number of publications highlight the necessity to consider universal design rules to create the furniture that is accessible to all regardless the age or mobility limitations (Østergaard 1994; Timlin and Rysenbry 2010). Though in the subject literature there is still a lack of wider studies 
conducted within the international scope. Thus, the purpose of this paper is to present the design requirements for age-friendly sitting furniture taking into consideration functional values of the product that are related to safety and comfort of use from the point of view of the international sample group. This is in line with the ultimate goal of supporting older adults' daily living and health through senior-friendly furniture. As the furniture for sitting differs significantly depending on the purpose of use, in the presented study we focused on chairs for dining rooms and armchairs. Those pieces of furniture can be used both in the private households and public assisted living facilities.

\section{METHODOLOGY}

\section{Study Design and Setting}

To gather data concerning the most crucial features of senior-friendly furniture for sitting, survey research was conducted among people aged 60+. The survey form was developed by experts representing various fields: wood technology, design, geriatrics, robotics, etc., from 9 Baltic Sea region countries. The survey form consisted of open-ended and closed questions regarding preferences and problems seniors face while using furniture located in bedrooms and living rooms. The results presented below refer to the questions concerning the evaluation of various design and functionality features of furniture for sitting, including dimensions, construction, functions, material selection, and the external form. The survey form was developed in the English language and next translated by professional translate offices into national languages to facilitate the process of gathering the data in the selected countries. The research constituted the part of the international study being developed within BaltSe@nioR and BaltSe@nioR 2.0 projects to provide knowledge supporting the development of new senior-friendly products dedicated both to private and public spaces.

\section{Participants and Survey Procedures}

The study was performed through surveys (both paper and electronic ones) and direct interviews. The researched population constituted of seniors living in 6 Baltic Sea region countries: Poland, Germany, Finland, Denmark, Lithuania, and Latvia. In each of the countries, non-probability samples were obtained through unrestricted self-selected survey (Fricker 2008). Project partners distributed the questionnaires using their own professional networks and personal contacts via e-mails, newsletters, websites, and social media (Facebook, LinkedIn, etc.). Additionally, various senior organizations have been contacted to facilitate reaching the target audience. Participants were asked to fill in the questionnaires if they were 60+ years old and forward it further to whom it might concern. Therefore, the authors managed to start the process of a snowball effect (Ugolini et al. 2020). Such distribution of surveys did not allow for personal identification of individual respondents. In those countries where an electronic version of the survey was used, the research was performed via professional online survey platforms - in Denmark (Survey Monkey and AskPeople), in Germany (Survey Monkey), and in Poland (Ankietka.pl). The percentage of responses achieved via electronic survey reached 100\% in Germany, $80 \%$ in Denmark and $40 \%$ in Poland. The method used in that case was a Computer-Assisted Web Interview (CAWI). The research that was done with the use of paper forms and direct interviews was done in Poland, Denmark, Finland, Latvia, and Lithuania. The percentage of respondents reached via paper surveys and direct interviews was $100 \%$ for Finland, 
Latvia, and Lithuania, 60\% for Poland, and 20\% for Denmark. All surveys were anonymous. The aim was to reach a minimum of 100 respondents in each of the participating countries.

Taking into account the percentage of completed surveys, a statistical analysis was conducted on the data obtained from 627 seniors. Women constituted $62 \%$ of the sample population, while men constituted $38 \%$ (Table 2). For the EU population the numbers were similar, in 2019 there was $57 \%$ of women and $43 \%$ of men living in the European Union. The researched population constituted of seniors living both in the urban and rural areas.

Table 2. Demographic Profile of the Respondents

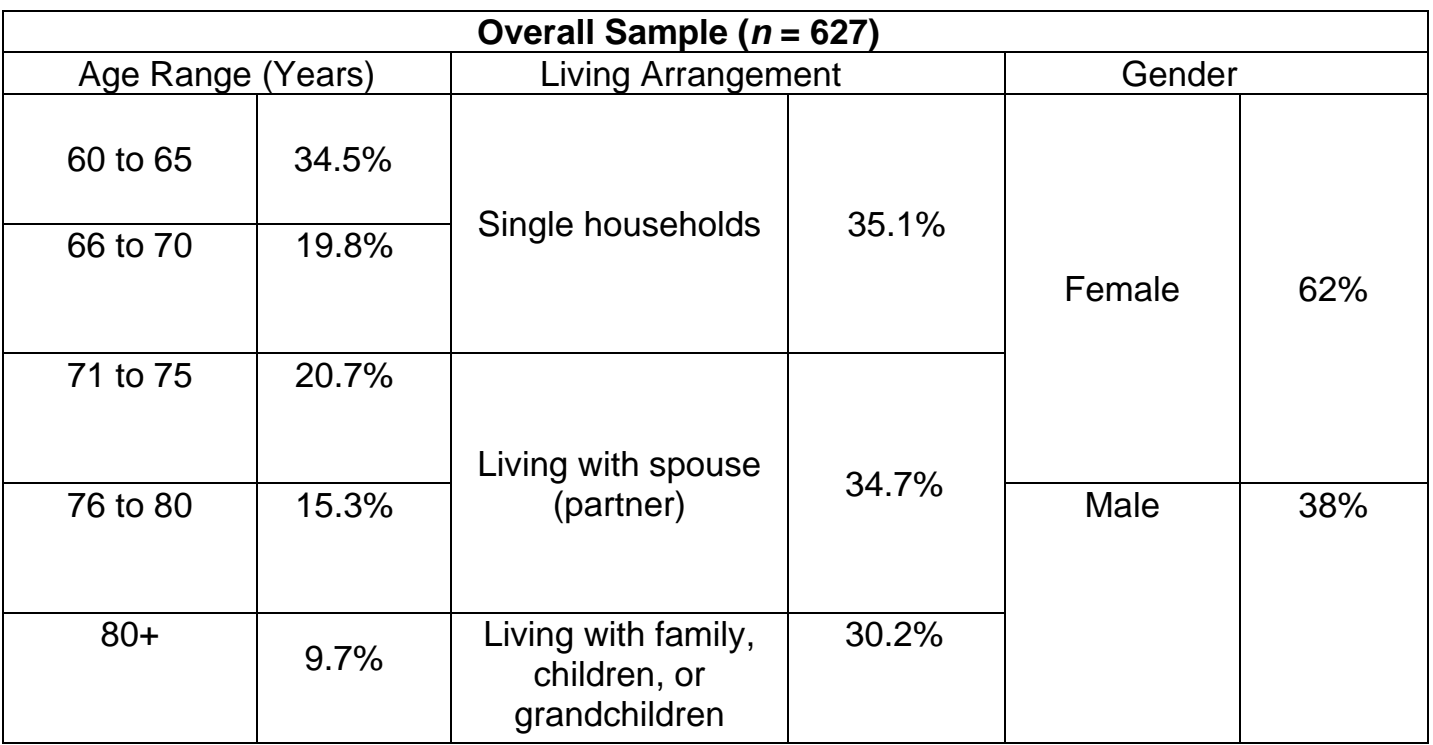

Source: Authors' own elaboration based on the performed survey research

\section{Analysis Procedures}

The questions analyzed in this paper were closed-ended questions, mostly of single choice. The questions concerned the following:

- "Which armchair do you prefer more: with low backrest reaching to the loins, with backrest reaching to the shoulders, with high backrest reaching above the head?";

- "Do you have an armchair with reclining/relax function?";

- "Would you like to have an armchair with reclining/relax function?";

- "Should your armchair be fully upholstered, with wooden elements or with metal elements?";

- "Which chair do you prefer more: fully wooden chair, a chair with upholstered backrest and seat, a chair with only seat upholstered?";

- "From which chair it is easier for you to get up from: one with armrests or without armrests?";

- "Would you like to have influence on the dimensions of the furniture prior the purchase? If yes, would you like to have influence on the height of the seat, on the width of the seat, on the depth of the seat?";

- "Could you rate on the scale from 1-5 the functional features of furniture for sitting that are the most important for you?";

- "Do you have a separate room dedicated for sleeping?". 
The gathered data were coded, implemented to the unified database, and subjected to statistical analysis. The coding was done by transferring each item of the questionnaire into a variable reflecting the answer of the respondent. Using the statistical grouping method, the characteristics of the needs and attitudes of seniors related to the analyzed subject were identified. In order to establish the relationship between the investigated variables and answers to the questions related to age-friendly furniture for sitting, analyzes were performed with the $\chi 2$ test of independence or with Fisher's exact test. The Z proportion test for columns was used as a post hoc test. The level of significance was $\alpha=$ 0.05. When analyzing the most preferred characteristic of furniture for sitting, the respondents were asked to evaluate each feature on a scale from 1 to 5 . To provide more visibility of the data achieved, the authors consolidated the results for the most important (evaluation 4 and 5) and least important (evaluation 1 and 2) furniture features. The statistical analysis was conducted using STATISTICA 13 PL software (Dell, Round Rock, TX, USA). Three main variables were taken into consideration - the age of respondents, the gender and their country of living.

The research questions concerned the recognition of the preferences of seniors regarding the design and construction features of chairs for dining rooms and armchairs. They were also to identify the similarities and differences concerning senior-friendly design and functionality features of furniture for sitting with regard to the age group, the gender and country of living. The results can constitute an inspirational source of knowledge for designers and furniture manufacturers to support them in the creation of age-friendly products and through this facilitate senior daily living.

\section{RESULTS}

The first issue investigated was the construction feature related to the height of the backrest. As much as $79 \%$ of respondents preferred high backrest reaching above the head of the user. Respondents in all studied countries presented a similar opinion (Fig. 1). In order to evaluate the relationship between the choice of the backrest and the country of living of the respondents, an analysis was performed with the Fisher exact test. The analysis showed no significant relationship between the variables, $p=0.083 ; \mathrm{V}=0.14$. Such a result means that the proportions of responses in the compared groups regarding the frequency of choosing a particular type of the backrest were similar. In each of the analyzed groups, the vast majority preferred chairs with a high backrest reaching above the head. The analysis made with the statistical grouping method with regard to the age of respondents indicated that it was an important construction issue for senior respondents of all ages (Fig. 2). Particularly it was an issue for respondents above 85 years old. In this age group over $90 \%$ of respondents like to have an armchair with the backrest reaching above the head. When the gender factor was taken into consideration it turned out that slightly bigger percentage of men (85\%) preferred to have an armchair with a backrest reaching above the head. For women participants a higher backrest was important for $76 \%$, still constituting the majority of the investigated sample. 


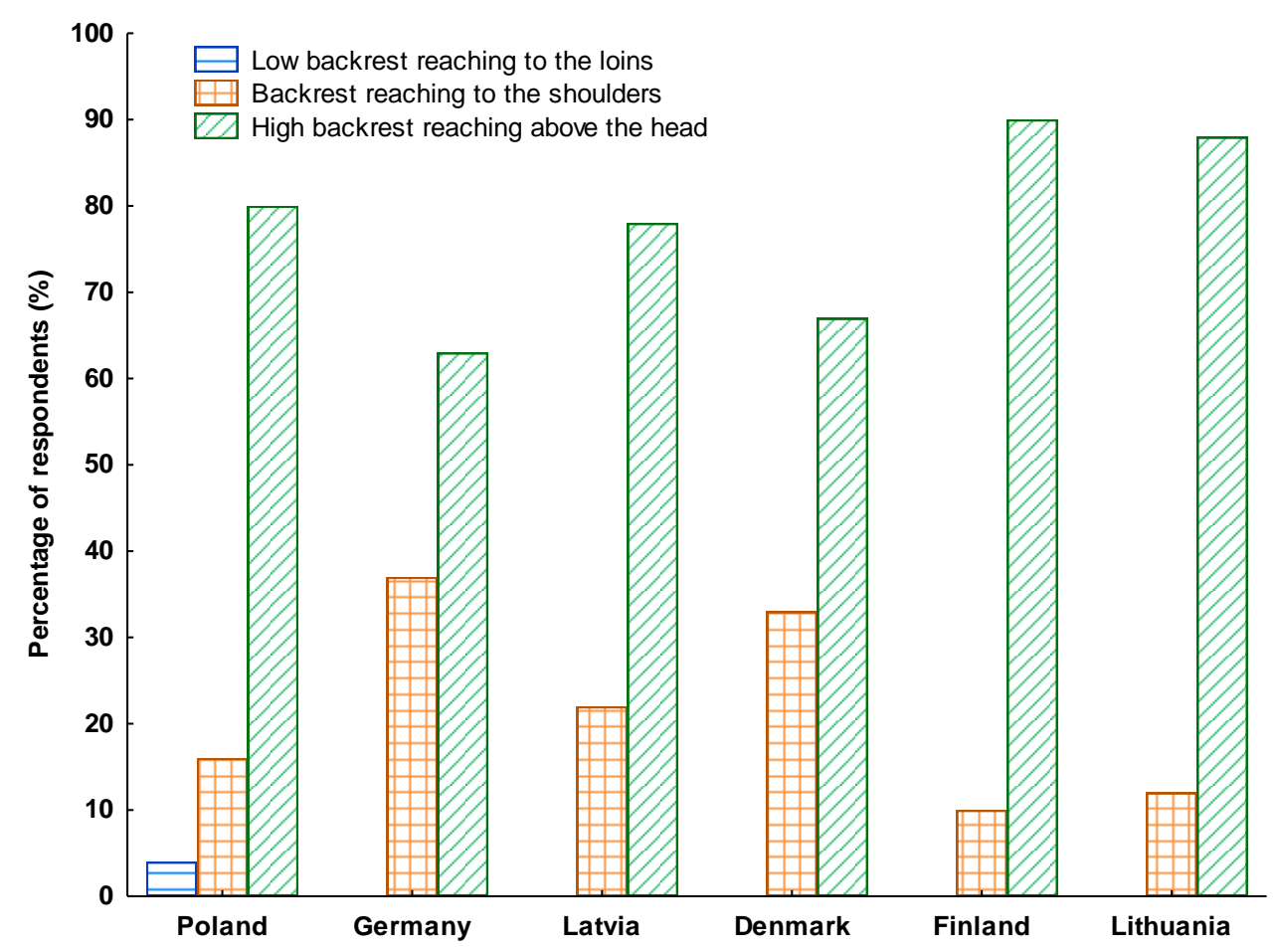

Fig. 1. Seniors' preferences concerning the height of the backrest with regard to respondents' country of living (source: Authors' elaboration based on the performed survey research)

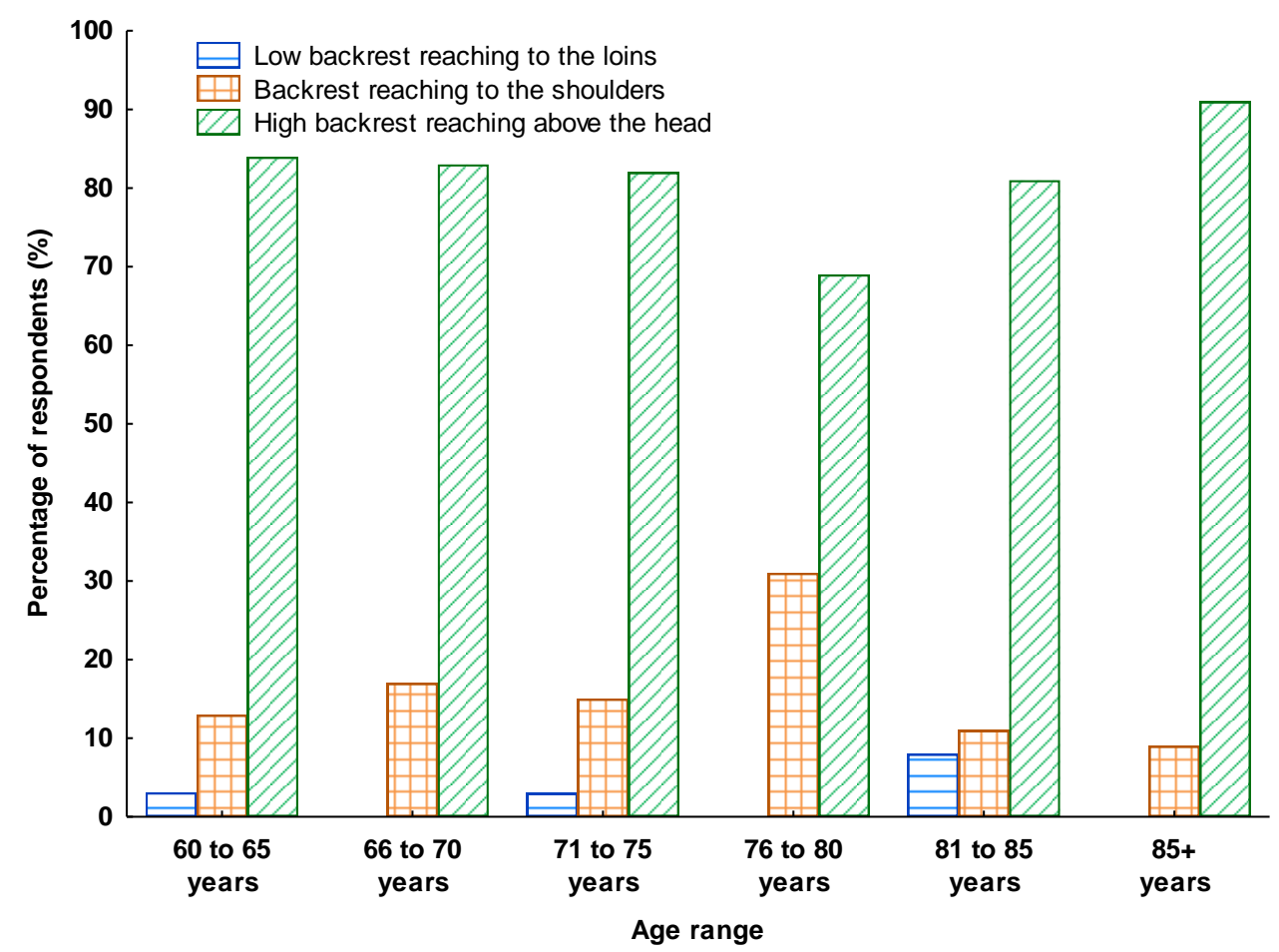

Fig. 2. Seniors' preferences concerning the height of the backrest with regard to respondents' age (source: Authors' elaboration based on the performed survey research)

To recognize senior users' needs and provide guidance for designing age-friendly armchairs, the authors decided to investigate the attitude of respondents towards increased 
functionality of the armchair in the form of a reclining/relax function. The number of respondents already having an armchair with the reclining function accounted for $23 \%$. Among the users who already have such an armchair, 92\% indicated they would love to still have an armchair with the reclining/relax function.

Some interesting remarks can be drawn from the data presented in Fig. 3. It shows the results on the desire to have an armchair with reclining/relax function with regard to respondents' country of living. The majority of respondents in Latvia, Poland (over 60\%), and Lithuania (over 80\%) would like to have an armchair with a relax function. However, in Germany, Denmark, and Finland the respondent response was different. Analysis with the Pearson $\chi^{2}$ test showed a significant relationship between the country of living of the respondents and the desire to have an armchair with reclining/relax function, $\chi^{2}(5)=$ $31.85 ; \mathrm{p}<0.001 ; \mathrm{V}=0.26$. In order to establish the nature of the relationship between the variables, an additional post hoc analysis was performed using the $\mathrm{Z}$ proportion test (with correction of the Bonferroni significance level). The analysis showed that the inhabitants of Lithuania, significantly more often than the inhabitants of Germany and Denmark, would like to have an armchair with a reclining/relax function $(p<0.05)$. In turn, the inhabitants of Denmark significantly less often than the inhabitants of Poland and Lithuania wanted to have such an armchair $(\mathrm{p}<0.05)$. Between the other groups, the differences in the frequency of the desire to have a chair with the relaxation function were statistically insignificant.

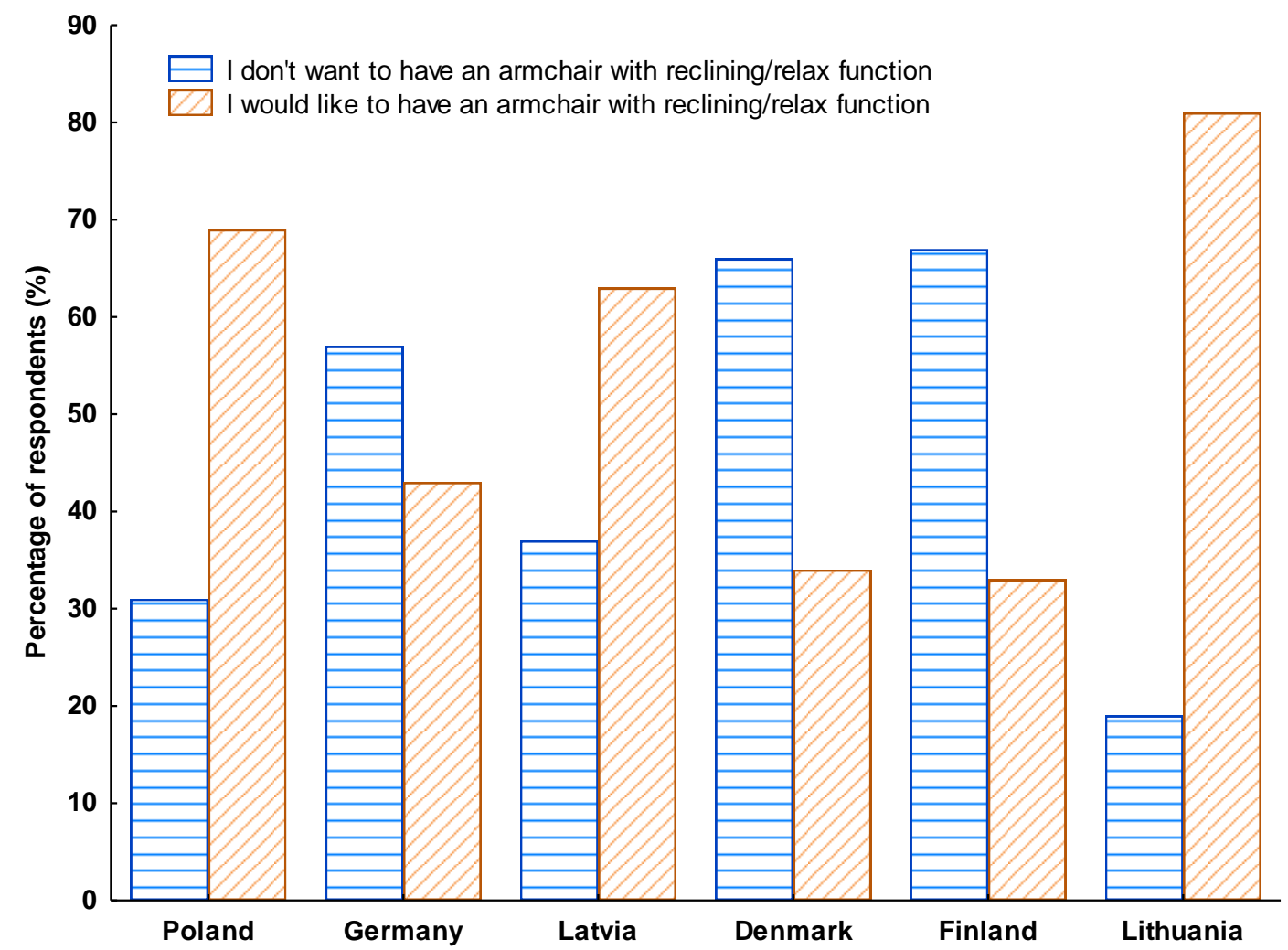

Fig. 3. Seniors' preferences concerning the willingness to have an armchair with reclining/relax function with regard to respondents' country of living (source: Authors' elaboration based on the performed survey research) 
Nevertheless, as far as age is the factor taken into account in the grouping method, clear evidence for the implementation of the reclining/relax function into armchairs is seen. In order to establish the relationship between the age of the respondents and the desire to have a chair with the reclining/relax function, the analysis was performed using the Pearson $\chi 2$ test. The analysis showed no significant relationships between the variables, $\chi 2(4)=$ 5.65; $\mathrm{p}=0.227 ; \mathrm{V}=0.11$. The results presented in Fig. 4 indicate that in all age groups over $60 \%$ of seniors would like to have an armchair that would allow them to adopt a comfortable, reclining posture while sitting in the armchair. The gender factor was not recognized as significant in this case. Both for men and women the majority of respondents: $67 \%$ and $63 \%$ respectively would like to have at their place of living an armchair with the reclining/relax function.

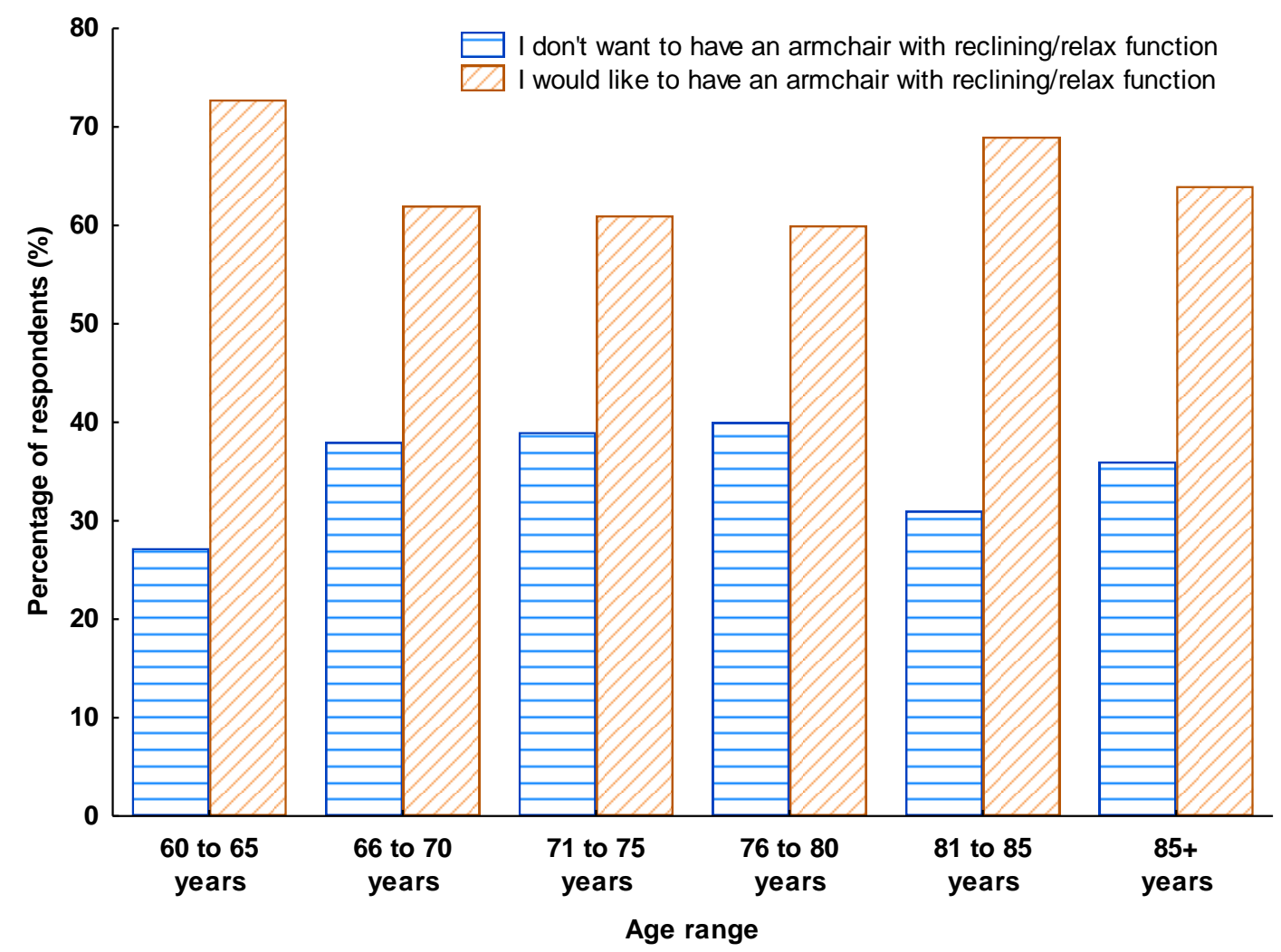

Fig. 4. Seniors' preferences concerning the wish to have an armchair with reclining/relax function with regard to respondents' age (source: Authors' elaboration based on the performed survey research)

When considering design features related to the external form of the furniture, the authors wanted to investigate the preferences concerning the visibility of materials used. It turned out that over $50 \%$ of respondents would like to have an armchair that is fully upholstered. The second most preferred material was wood, used for elements such as for example supports of the armrests. This option was chosen by $29 \%$ of respondents. The least popular possibility was manufacturing the additional element from metal. Only $18 \%$ of respondents admitted they would like to have an armchair with metal elements.

The above-described issue has been investigated in more detail taking into consideration the age of respondents. In order to establish the relationship between the age of the respondents and the choice of the material visible on the armchair, an analysis was 
performed using the Pearson $\chi 2$ test. The analysis did not show any significant relationships for the selection of the fully upholstered armchair, $\chi^{2}(4)=1.53 ; \mathrm{p}=0.821 ; \mathrm{V}=0.10$; armchair with wooden elements, $\chi 2(4)=8.97 ; \mathrm{p}=0.062 ; \mathrm{V}=0.24$ and armchair with metal elements, $\chi^{2}(4)=3.29 ; \mathrm{p}=0.511 ; \mathrm{V}=0.15$. This indicates that the proportions of responses were similar in each of the analyzed groups. The obtained results show that in all age groups the majority of seniors want to have an armchair that is fully upholstered (Fig. 5).

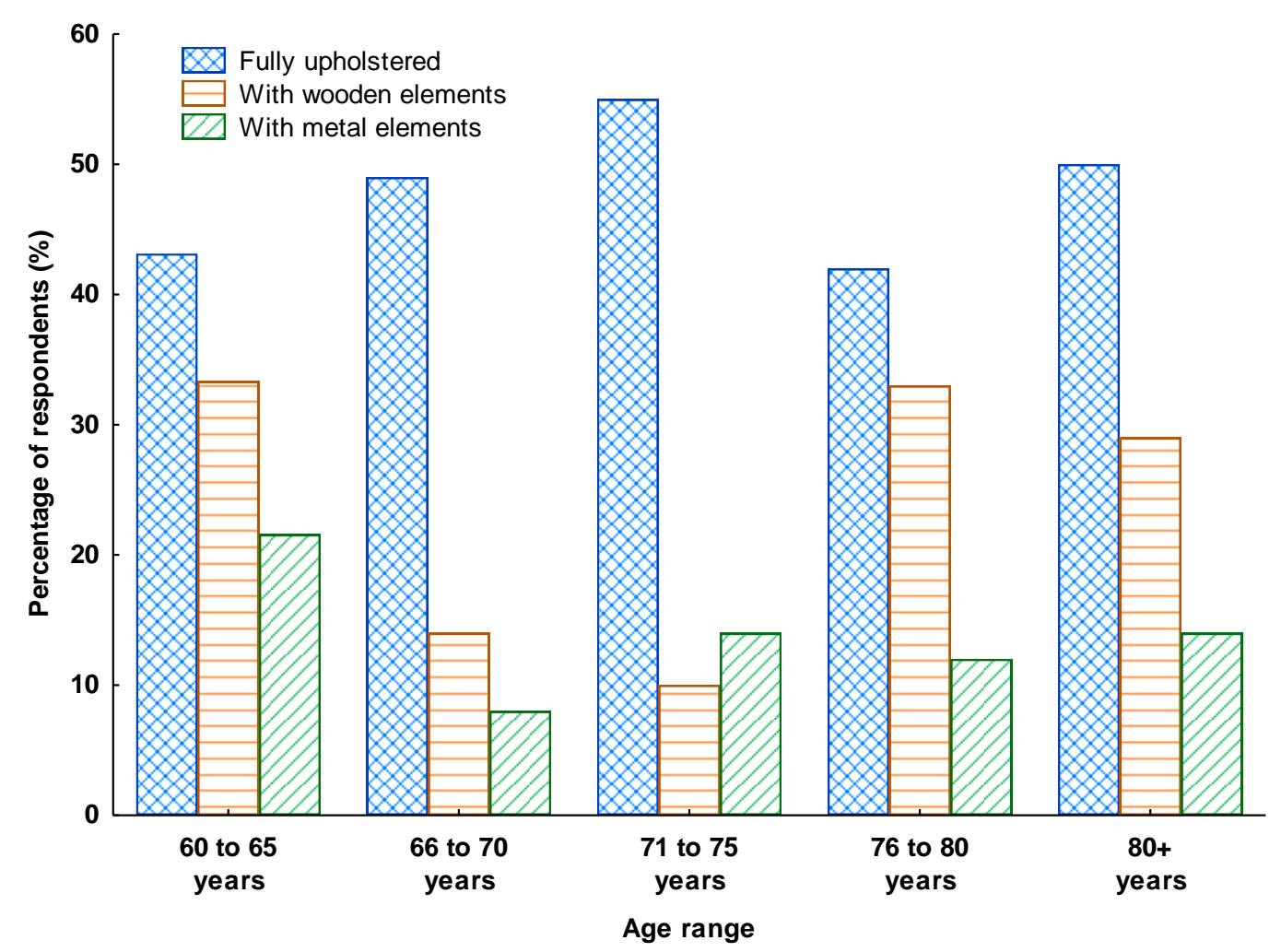

Fig. 5. Seniors' preferences concerning the types of materials to be visible in their armchair with regard to respondents' age (source: Authors' elaboration based on the performed survey research)

Apart from armchairs, chairs constitute an important furniture group when designing private and public spaces for seniors too. Thus, the authors also decided to gather data about their preferred design, construction, and functionality. The authors started by the recognition of preferred construction features. As many as $62 \%$ of respondents would like to have a chair that has both an upholstered seat and a backrest. Merely $27 \%$ would prefer the chair with only the seat upholstered, and the lowest number of respondents (11\%) would choose the chair that is fully wooden.

Another important design and construction issue is equipping the chair with armrests. The data obtained revealed that $76 \%$ of people aged $60+$ admit that it is easier for them to stand up and sit down when the chair is equipped with armrests. The more comprehensive analysis of the data from six countries showed that over $90 \%$ of seniors living in Denmark and Lithuania confirmed that armrests facilitate the process of using the chair (Fig. 6). Also when the gender factor was analyzed no significant impact of the gender on this preference was recognized. For both, men and women being respondents of the 
survey, it was easier to get up from the chair having the armrests. As many as $81 \%$ of men and $73 \%$ of surveyed women preferred this type of construction as the one facilitating the process of getting up and sitting down.

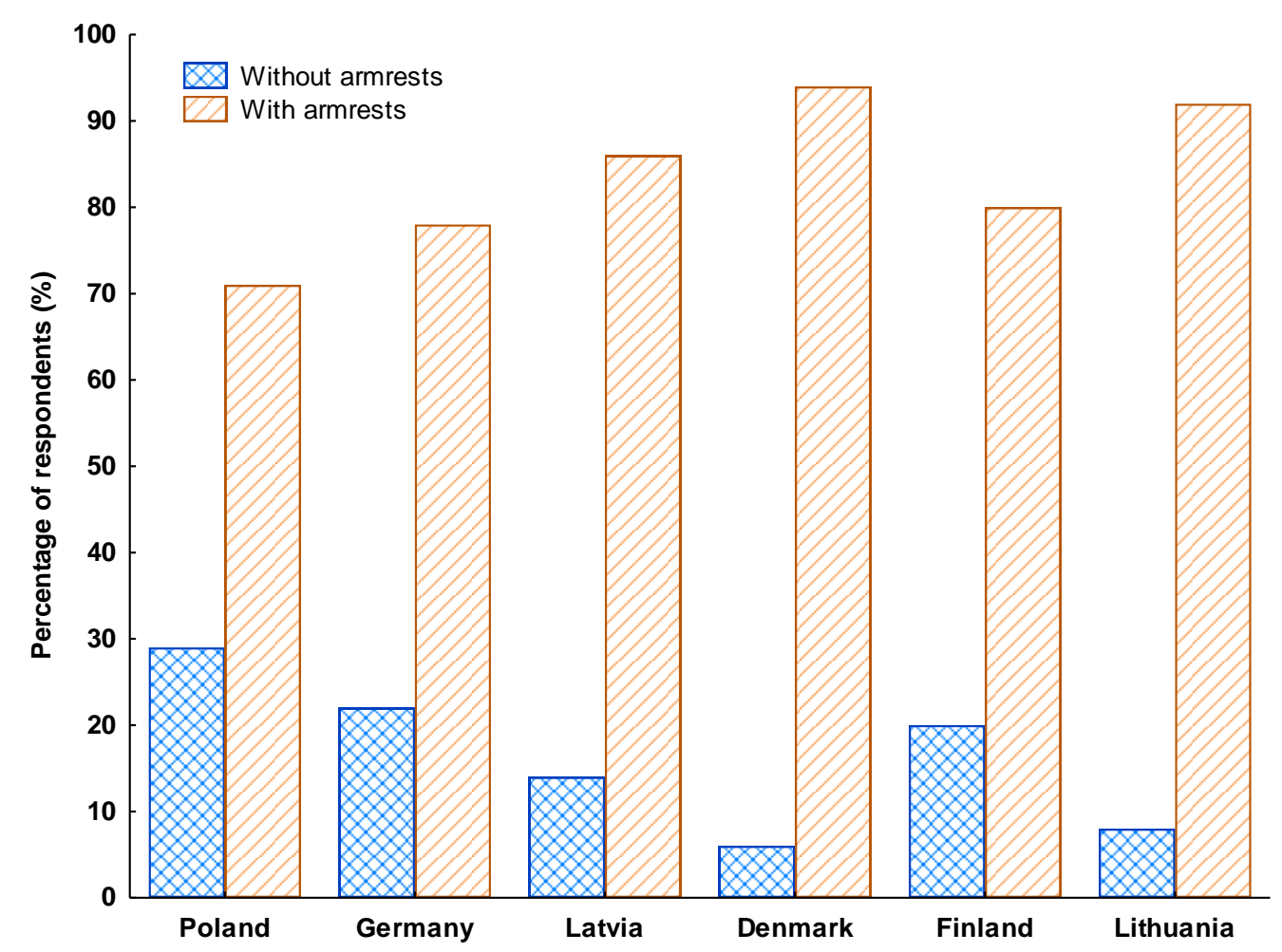

Fig. 6. Seniors' preferences concerning the construction features of the chair with regard to respondents' country of living (source: Authors' elaboration based on the performed survey research)

Additionally, the results of the statistical analysis taking into consideration the age of respondents point out that this is a valuable functionality feature for seniors of all ages (Fig. 7). However, unexpectedly it turned out there was no relationship between the age and the opinion that armrests support the process of standing up and sitting down. This means that in the oldest age groups the number of users admitting it is easier to get up when a chair has armrests was not higher than in the younger age groups. Analysis with Pearson's $\chi 2$ test did not show a significant relationship between the age of the respondents and the choice of a chair with or without armrests, $\chi 2(4)=3.12 ; \mathrm{p}=0.538 ; \mathrm{V}=0.08$. This means that the proportions of choosing a chair with or without armrests were similar in the analyzed age groups.

As many as $60 \%$ of respondents would like to have influence on the height of the seat before buying the furniture for sitting. Furthermore, a considerable group of respondents (56\%) admitted they would like to have influence on the depth of the seat. It is important to note that over half of the respondents (51\%) admitted they would like to have influence also on the width of the seat. Such high percentage values indicate that ensuring mass customization of functional dimensions of furniture when providing products for the senior population is an appreciated feature. 


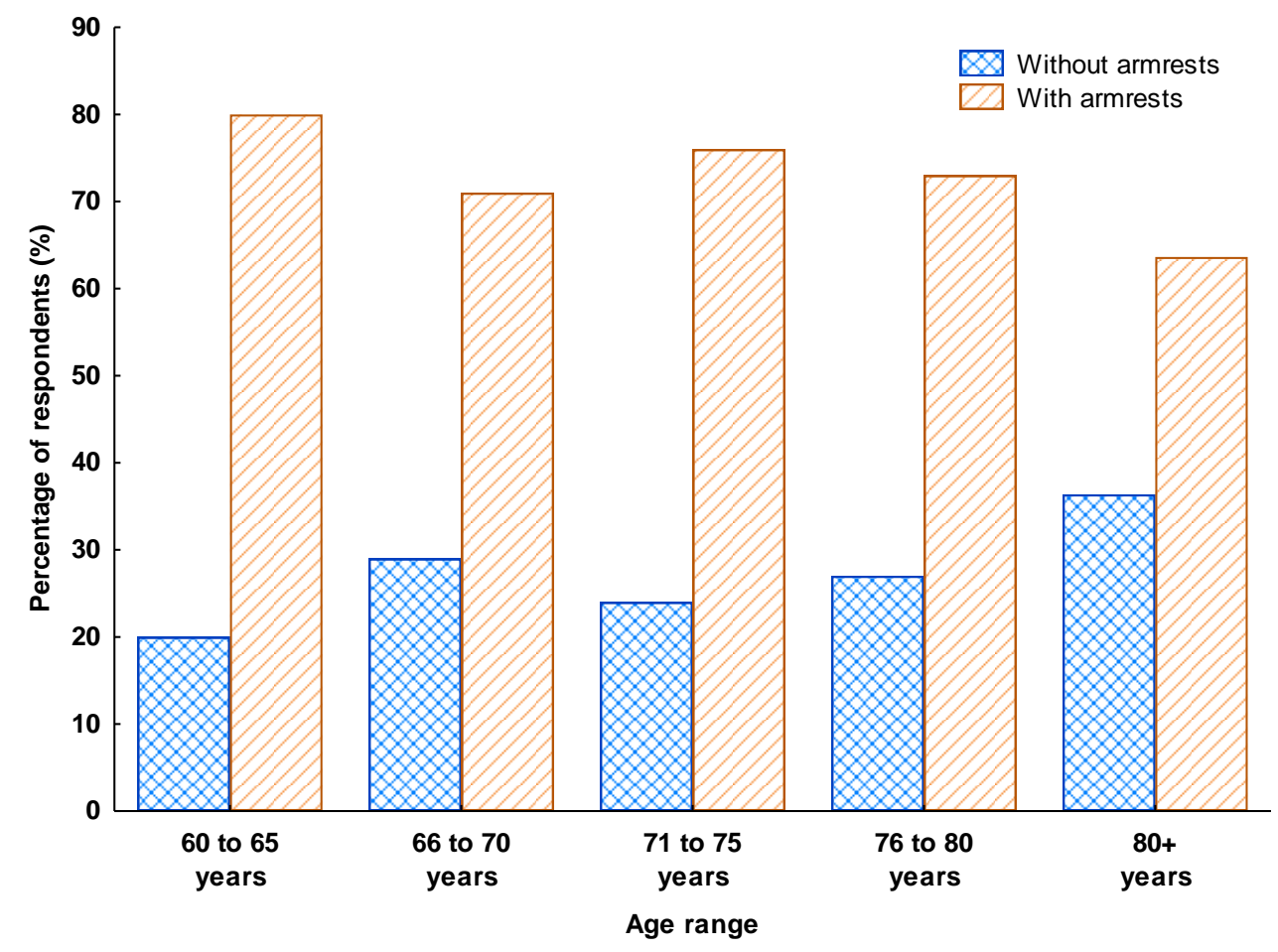

Fig. 7. Seniors' preferences concerning the construction features of the chair with regard to respondents' age (source: Authors' elaboration based on the performed survey research)

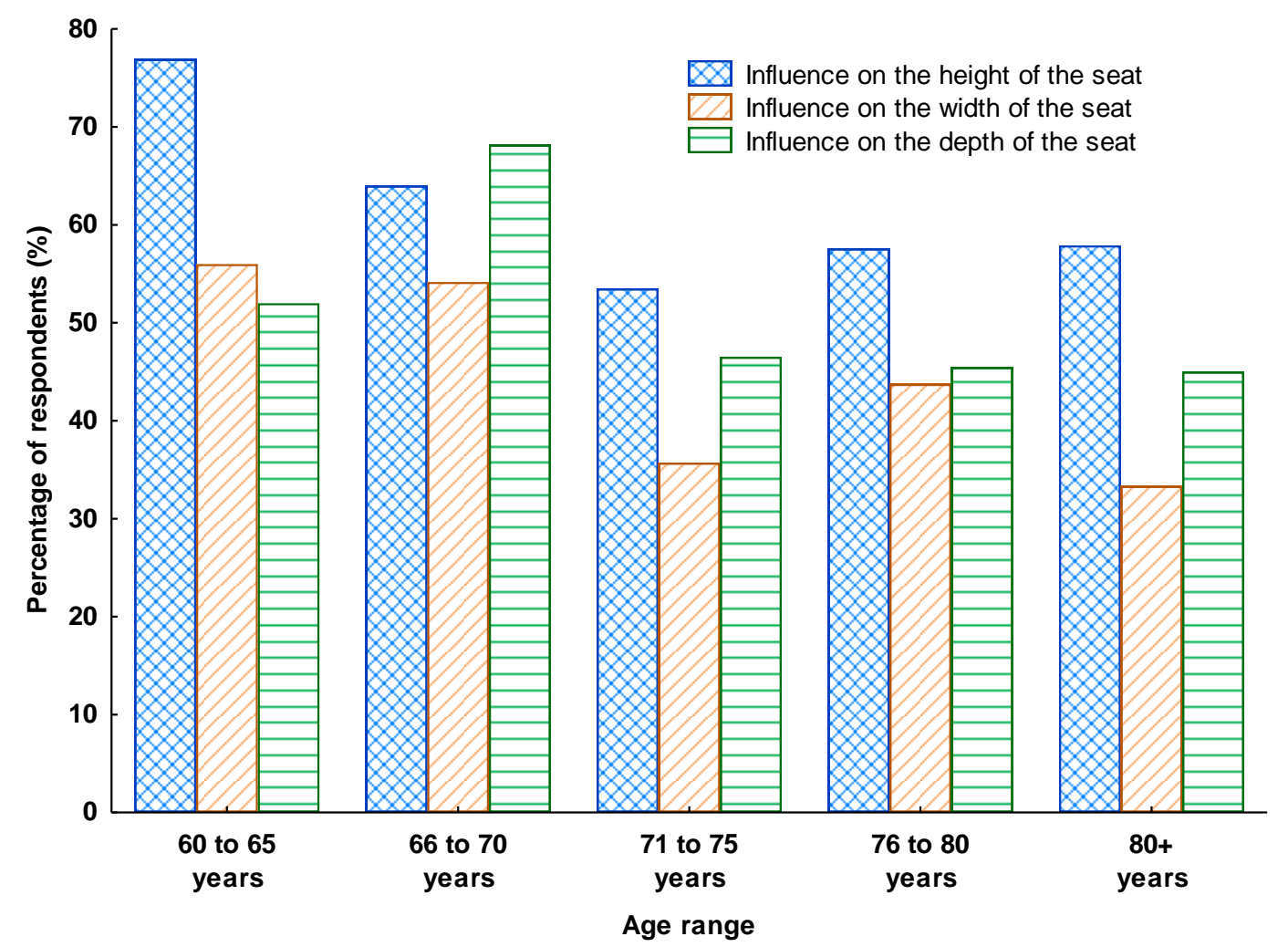

Fig. 8. Types of chair dimensions respondents would like to have influence on before buying (source: Authors' elaboration based on the performed survey research) 
Additional analysis with regard to the age factor shows that the younger population of seniors more often sees the necessity to ask for the adjustment of functional dimensions of furniture for sitting than the older senior generations (Fig. 8). As many as $77 \%$ of respondents aged 60 to 65 would like to have influence on the height of the seat prior the purchase. In turn almost $70 \%$ of respondents aged 66 to 70 would like to have influence on the depth of the seat. Taking into consideration the gender factor revealed that women more often than men expressed the willingness to have influence on the functional dimensions of furniture for sitting prior the purchase. As many as $70 \%$ of women respondents wanted to have an influence on the height of the seat, $66 \%$ on the depth of the seat and $61 \%$ on the width of the seat. While for men this number was lower and reached $44 \%$ of men respondents wanting to decide about the height of the seat prior purchase, $40 \%$ on the depth of the seat and only $37 \%$ on the width of the seat.

The last issue to consider is the recognition of the functional features of furniture that can add value to the offered products. In order to acquire the knowledge on the most preferred characteristic, the authors asked respondents to evaluate each feature in the scale from 1 to 5. As Fig. 9 and Tables 3 and 4 illustrate, seniors living in different Baltic Sea countries value similar features in furniture. Most valued features are related to the long lifetime and low maintenance of the product (durability and stain resistant).

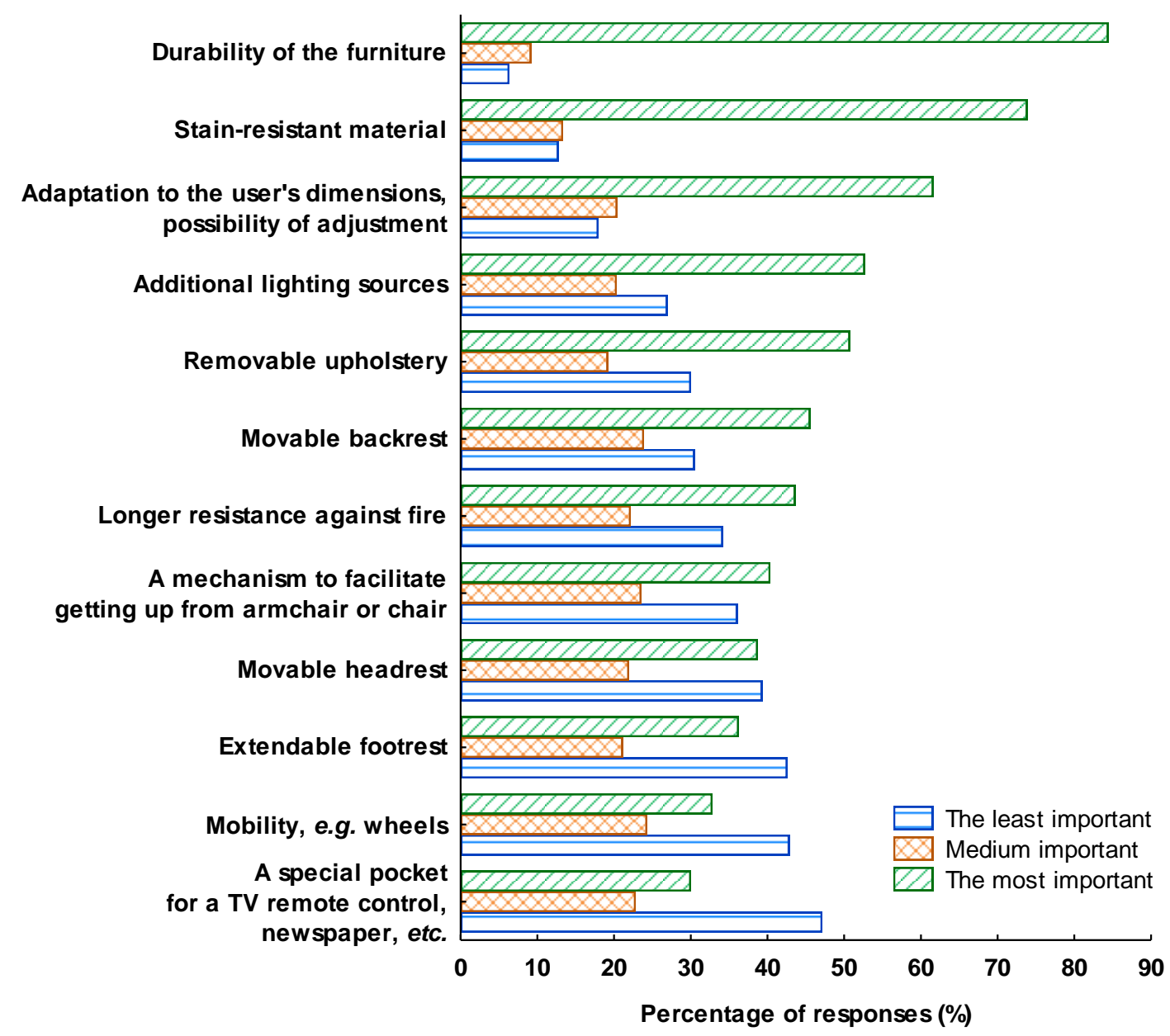

Fig. 9. Evaluation of functionality features of furniture for sitting (source: Authors' elaboration based on the performed survey research) 
There are also similar needs for adjustment of the dimensions. However, slight differences can be found between different countries and age groups (Fig. 9, Tables 3 and 4). In order to establish the relationship between the age of the respondents and the assessment of the importance of individual furniture features, an analysis was performed using the $\chi 2$ independence test. The analysis showed significant differences in age groups for durability of the furniture, a mechanism to facilitate getting up from an armchair or a chair, as well as for mobility. The strength of the effect was weak. In order to establish the nature of the differences between the age groups, post hoc analysis was carried out with the $\mathrm{Z}$ proportion test. Among people aged 71 to 75 years, durability of the furniture was more often assessed as important or very important than in the group of 76 to 80 years. A mechanism to facilitate getting up from armchair or chair was more often assessed as important or very important in the 71 to 75 and $80+$ age group than in the 60 to 65 age group. Mobility was more important in the 76 to 80 age group than in the 60 to 65 and 71 to 75 age group. The detailed results of the analyzes are presented in Table 3.

Table 3. Evaluation of Functionality Features of Furniture for Sitting with Regard to the Age of Respondents (\% of Respondents)

\begin{tabular}{|c|c|c|c|c|c|c|c|c|}
\hline \multirow[t]{2}{*}{ Functionality Feature } & \multicolumn{5}{|c|}{ Age Range (Years) } & \multirow[t]{2}{*}{$x^{2}$} & \multirow[t]{2}{*}{$p$} & \multirow[t]{2}{*}{ V } \\
\hline & $\begin{array}{c}60 \text { to } \\
65\end{array}$ & $\begin{array}{c}66 \text { to } \\
70\end{array}$ & $\begin{array}{c}71 \text { to } \\
75\end{array}$ & $\begin{array}{c}76 \text { to } \\
80\end{array}$ & $80+$ & & & \\
\hline Durability of the furniture & $89_{a, b}$ & $83 a, b$ & $93 a$ & $71_{b}$ & $84 a, b$ & 9.55 & 0.049 & 0.18 \\
\hline Stain-resistant material & 79 & 70 & 75 & 66 & 69 & 3.78 & 0.437 & 0.11 \\
\hline $\begin{array}{l}\text { Adaptation to the user's } \\
\text { dimensions, possibility of } \\
\text { adjustment }\end{array}$ & 60 & 65 & 67 & 71 & 42 & 6.14 & 0.189 & 0.15 \\
\hline Removable upholstery & 55 & 52 & 58 & 50 & 33 & 5.32 & 0.256 & 0.13 \\
\hline Additional lighting sources & 54 & 58 & 48 & 51 & 32 & 6.32 & 0.176 & 0.14 \\
\hline Longer resistance against fire & 44 & 42 & 39 & 58 & 32 & 4.48 & 0.345 & 0.13 \\
\hline Movable headrest & 42 & 43 & 41 & 32 & 27 & 3.55 & 0.470 & 0.11 \\
\hline Movable backrest & 41 & 57 & 44 & 44 & 38 & 5.04 & 0.283 & 0.14 \\
\hline Extendable footrest & 38 & 42 & 40 & 36 & 29 & 1.67 & 0.796 & 0.07 \\
\hline $\begin{array}{l}\text { A mechanism to facilitate } \\
\text { getting up from armchair or } \\
\text { chair }\end{array}$ & $32 a$ & $47 a, b$ & $53 b$ & $47 a, b$ & $53 b$ & 9.89 & 0.042 & 0.18 \\
\hline $\begin{array}{l}\text { A special pocket for a TV } \\
\text { remote control, newspaper, } \\
\text { etc. }\end{array}$ & 30 & 32 & 41 & 28 & 21 & 3.57 & 0.468 & 0.11 \\
\hline Mobility, e.g., wheels & $28 a$ & $34 a, b$ & $25 a$ & $59 b$ & $41_{a, b}$ & 13.79 & 0.008 & 0.21 \\
\hline
\end{tabular}

Columns that do not divide the letter index differ from each other at the level of $p<0.05$ (Bonferroni correction)

Source: Authors' elaboration based on the performed survey research

Table 4 presents the percentage distribution of responses along with the $\chi 2$ independence test regarding the importance of individual furniture features depending on the country of living of respondents. The analysis showed a significant relationship 
between the functional assessment of a given furniture feature and the country for most of the analyzed features (weak effects).

Table 4. Evaluation of Functionality Features of Furniture for Sitting with Regard to the Country of Living of Respondents (\% of Respondents)

\begin{tabular}{|c|c|c|c|c|c|c|c|c|c|}
\hline \multirow{2}{*}{$\begin{array}{l}\text { Functionality } \\
\text { Feature }\end{array}$} & \multicolumn{6}{|c|}{ Country } & \multirow[t]{2}{*}{$x^{2}$} & \multirow[t]{2}{*}{$p$} & \multirow[t]{2}{*}{ V } \\
\hline & Poland & Germany & Latvia & Denmark & Finland & Lithuania & & & \\
\hline $\begin{array}{l}\text { Durability of } \\
\text { the furniture }\end{array}$ & $89 a$ & $68 b$ & $81_{a, b}$ & $n / d$ & $83_{a, b}$ & $76_{a, b}$ & 11.90 & 0.014 & 0.19 \\
\hline $\begin{array}{l}\text { Stain- } \\
\text { resistant } \\
\text { material }\end{array}$ & 74 & 68 & 64 & $\mathrm{n} / \mathrm{d}$ & 75 & 85 & 4.90 & 0.298 & 0.12 \\
\hline $\begin{array}{l}\text { Adaptation to } \\
\text { the user's } \\
\text { dimensions, } \\
\text { possibility of } \\
\text { adjustment }\end{array}$ & $68 \mathrm{a}$ & $\mathrm{n} / \mathrm{d}$ & $63_{a, b}$ & $\mathrm{n} / \mathrm{d}$ & $25_{a, b}$ & $39 b$ & 18.75 & $<0.001$ & 0.26 \\
\hline $\begin{array}{l}\text { Additional } \\
\text { lighting } \\
\text { sources }\end{array}$ & 50 & 67 & 55 & $\mathrm{n} / \mathrm{d}$ & 25 & 64 & 7.59 & 0.108 & 0.15 \\
\hline $\begin{array}{l}\text { Movable } \\
\text { backrest }\end{array}$ & $47_{a, b}$ & $\mathrm{n} / \mathrm{d}$ & $58 b$ & $\mathrm{n} / \mathrm{d}$ & $\mathrm{n} / \mathrm{d}$ & $28 a$ & 6.82 & 0.033 & 0.16 \\
\hline $\begin{array}{l}\text { Removable } \\
\text { upholstery }\end{array}$ & $47 a$ & $36 a$ & $59 a, b$ & $n / d$ & $38 a, b$ & $78 b$ & 17.62 & 0.001 & 0.23 \\
\hline $\begin{array}{l}\text { A mechanism } \\
\text { to facilitate } \\
\text { getting up } \\
\text { from } \\
\text { armchair or } \\
\text { chair }\end{array}$ & $43 a$ & $12 b$ & $54 a$ & $\mathrm{n} / \mathrm{d}$ & $71_{a}$ & $29_{a, b}$ & 17.09 & 0.002 & 0.23 \\
\hline $\begin{array}{l}\text { Movable } \\
\text { headrest }\end{array}$ & 42 & 22 & 29 & $\mathrm{n} / \mathrm{d}$ & 25 & 41 & 6.23 & 0.183 & 0.14 \\
\hline $\begin{array}{l}\text { Extendable } \\
\text { footrest }\end{array}$ & $40_{a}$ & $7 b$ & $37_{a, b}$ & $\mathrm{n} / \mathrm{d}$ & $38_{a, b}$ & $37_{a, b}$ & 10.77 & 0.029 & 0.18 \\
\hline $\begin{array}{l}\text { Longer } \\
\text { resistance } \\
\text { against fire }\end{array}$ & $38 a$ & $n / d$ & $53 a, b$ & $n / d$ & $57_{a, b}$ & $62 b$ & 9.36 & 0.025 & 0.18 \\
\hline $\begin{array}{l}\text { Mobility, e.g., } \\
\text { wheels }\end{array}$ & $29 a$ & $19 a$ & $58 b$ & $\mathrm{n} / \mathrm{d}$ & $63_{a, b}$ & $41_{a, b}$ & 17.71 & 0.001 & 0.23 \\
\hline $\begin{array}{l}\text { A special } \\
\text { pocket for a } \\
\text { TV remote } \\
\text { control, } \\
\text { newspaper, } \\
\text { etc. }\end{array}$ & 29 & 14 & 40 & $n / d$ & 38 & 39 & 7.01 & 0.135 & 0.14 \\
\hline
\end{tabular}

$\mathrm{n} / \mathrm{d}$ - no data available on the individual feature in a given country

Columns that do not divide the letter index differ from each other at the level of $p<0.05$

(Bonferroni correction)

Source: Authors' elaboration based on the performed survey research

The percentage of Poles who assessed durability of the furniture as important or very important was significantly higher than the percentage of Germans. Adaptation to the user's dimensions and the possibility of adjustment was significantly more often assessed 
as important or very important among Poles than among Lithuanians. Lithuanians less often than Latvians indicated movable backrest as an important or very important functionality, while they more often assessed removable upholstery as important or very important compared to Poles and Germans. The Germans significantly less often pointed to the importance of a mechanism to facilitate getting up from armchair or chair compared to Poles, Latvians, and Finnish - in these groups this feature was assessed as important or very important by 43 to $71 \%$ of the respondents. Extendable footrest was significantly more often considered important or very important in the group of Poles than in the group of Germans. In turn, longer resistance against fire was a more important feature in the group of Lithuanians than Poles. Latvians more often than Poles and Germans indicated the importance of mobility.

\section{DISCUSSION}

For many years, seniors as a customer group have been neglected and forgotten by the market. The change in the purchase behaviors observed when a new generation of baby boomers reaches the senior age of $60+$ has caused an increased interest in the recognition of the needs of senior users. Because there are not many resources dealing with this subject and as the senior population is diversified, manufacturers may encounter serious problems in adjusting the product offer to the needs of the target group. In contrast, it is important to try to implement the universal design rules allowing for the creation of products that would be accessible to the biggest possible group regardless the age or mobility limitations.

One of the oldest definitions of design "form follows function" by Sullivan (1896) can be also observed in the results of this research. The majority of seniors in all analyzed countries indicated that they would like to have an armchair with the backrest reaching above the head. As they mentioned during the interviews and when answering the openended questions, it was mainly due to the increased comfort during relaxing and the possibility of having a short nap during the day. The possibility to lie down the head during the time of relaxation is also a comfortable option for other age groups that is confirmed by a number of studies on the comfort of sitting while having a headrest available.

As armchairs are mainly used during a time of relaxation, the authors were wondering whether the reclining/relax function implemented in the furniture would meet with the acceptance of senior users. It turned out that for the users who already have such an armchair, over $90 \%$ indicated they would love to still have one. This is a clear indication of how appreciated this function is for the senior users, being at the same time valuable hint for furniture designers. When it comes to the users who do not have such option in their armchairs yet, maybe it would be justified to prepare the communication actions allowing the users to try out this feature and build their own experiences. In some other further work, maybe the works should go towards the minimizing of the dimensions of such furniture, as those available currently on the market are quite big and sometimes might not be suitable in terms of dimensions (Dzięgielewski and Fabisiak 2005). The third thing that should be considered here is the user friendliness of the manner of using the option: does it require much energy to recline the furniture and how this process is designed (by a handle, a button etc.) are important considerations.

The identified differences in the preferences concerning the willingness to have an armchair with the recline/relax function between the analyzed countries (Fig. 3) might be connected with the type of furnishing in the living room and the existence of a separate 
room for sleeping. The results of our research indicate that in the group of respondents who did not want to have an armchair with the relaxing function as much as $63 \%$ had a separate room dedicated for sleeping. When there was a separate room dedicated for sleeping in the household, the sofa in the living room could be used for daytime naps. In contrast, when the sofa was used as a bed on a daily basis, another piece of furniture needed to take the function for taking daytime naps. In that case respondents were more willing to have an armchair with a relaxing function. As this issue is connected with the lifestyle and economic conditions on the typology of rooms in a household, it needs to be further investigated to recognize more details behind such customers' decisions.

The relaxing mode of using the armchairs is also underlined by the results showing that half of the analyzed seniors would like to have an armchair that is fully upholstered (Fig. 5). They state that this evokes the feeling of coziness, warmth, and pleasure while touching the furniture and thus helping to relax more easily. The highly appreciated upholstery materials constitute another challenge for designers while designing seniorfriendly furniture. Namely they need to consider the solutions allowing for the easy maintenance of cleanliness. This could be connected either with the function of the removal of the upholstery to wash it or providing stain-resistant material allowing for longer periods of furniture cleanliness. It is also worth highlighting that the second most preferred material was wood, used for elements such as for example supports of the armrests. The high and positive evaluation of wood as a material used for senior-friendly furniture is also confirmed by other research. It is connected with the positive associations toward wood and its characteristics being the material that is warm and pleasant to touch, reminding seniors also about nature (Fabisiak and Hrovatin 2014). The presence of upholstery materials was also underlined when recognizing the preferable materials to be used in chairs. Again, the majority of seniors indicated the wish to have both the seat and the backrest upholstered. The achieved results indicate that the comfort of use is of paramount importance for the users, especially when using the same furniture for many hours a day.

Furthermore, it is interesting to note that a majority of users in all studied countries wished for a backrest of the armchair reaching above the head of the user. That was observed especially in a group of seniors aged $85+$. This design requirement may be derived from the changes in a daily routine associated with the process of the aging of the human body. People at the later stage of life tent to fall asleep for short moments during the day for example while sitting in the armchair. A number of researchers (e.g. Goldman et al. 2008; Xin et al. 2020) have shown that while getting older some typical age-related changes occur in sleep architecture and sleep patterns. Due to these sleep architecture changes, for example patients with dementia may have excessive daytime sleepiness (Cooke and Ancoli-Israel 2011). Having a higher backrest prevents the head of a senior from falling back while daytime naps in the armchair and makes those naps more comfortable, especially when the armchair side head supports are applied.

Another important construction feature that should be taken into consideration when designing senior-friendly furniture for sitting is the presence of armrests. As many publications indicate that seniors meet difficulties when standing up and sitting down, the current authors wanted to verify whether the presence of armrests would facilitate the process. The results presented in Figs. 6 and 7 show that the majority of users in all analyzed countries and in all analyzed age groups considered the existence of armrests as a preferable feature of senior-friendly furniture. Nevertheless, it was surprising to notice there was no connection found between the age and the belief that armrests support the process of standing up and sitting down. This means that for the oldest age groups the 
number of users admitting it is easier to get up when a chair has armrests is not higher than in the younger age groups. One explanation might be that this user group has furniture that are otherwise supporting. However, it can also be associated with the fact that in the sample group there are various generations of seniors. There are representatives of the World War II/interwar period generation and the baby boomer generation. The World War II/interwar period generation is used to harsh living conditions; this is a modest generation that does not require too much from external environments and tries not to cause problems to others. Individuals of this generation are loyal and disciplined (Richert-Kaźmierska and Stankiewicz 2013; Richert-Kaźmierska 2014). This is also reflected in the results obtained. Even though this group of users is supposed to feel the greatest discomfort while using furniture, the representatives of this group did not complain more than the younger generations.

One of the most important challenges when designing furniture, such as chairs or armchairs, is the adaptation of the functional dimensions of the furniture to the changing anthropometric dimensions of an ageing population, as well as to the needs arising from the reduced physical activity and motor skills. The ageing-related difficulties in standing up and sitting down are among the most frequently mentioned by senior users of furniture. Anthropometric studies of the Polish population have shown that senior women are shorter, heavier, have wider shoulders, and much larger torso circumference (chest, waist, and hips) than younger women (Kalka 2001). Similar results, establishing the smaller height dimensions and the larger circumference dimensions for senior women, are presented by Jarosz (1998). Of course this anthropometric change is very much individually based and may depend on many factors such as genetic, environmental, sociocultural conditions, lifestyle, health, and functional status, to name just a few. The differences between the height dimensions of younger and older populations are mainly connected with the spinal deformity and thinning of the intervertebral discs (Perissinotto et al. 2002) or bone degenerative diseases (Gavriilidou et al. 2015). Still the general, significant trend is observed of decreasing height dimensions when getting older. The remarkable entity of height decrease was observed for example in the Italian study of Perissinotto et al. 2002 (2 to $3 \mathrm{~cm} /$ decade) that was comparable with the results of other Italian and international surveys: the Euronut Seneca Study reported a height decrease in both men and women of 1 to $2 \mathrm{~cm}$ in 4 years, i.e. 2.5 to $5 \mathrm{~cm} /$ decade. For Swedish seniors, Dey et al. (1999) quantified a mean decrement of 4 to $5 \mathrm{~cm}$ over 25 years. Baumgartner et al. (1995) reported a decrease of 0.5 to $1.5 \mathrm{~cm} /$ decade. The users' preferences derived from those anthropometric changes are also seen in the results of the current research. As presented in Fig. 8, the majority of respondents would like to have the influence on the height of the seat before buying the furniture for sitting. This is connected both with the difficulties with sitting down and standing up and with the changing dimensions of the human body. Additionally, also over half of respondents stated they would like to have the influence on the depth of the seat. They argued this by stating that often the seat is too deep and they cannot support their spine with the help of the backrest in a comfortable manner. Instead, in order to minimize the depth of the seat, they need to support their spine with additional pillows. It is also important to highlight that the anthropometric dimensions of a human body are significantly different for men and women, especially in the later stages of life (Jarosz 1998, Kalka 2001). The majority of women respondents admitted the furniture they use now is not comfortable for them and they would like to have influence on the functional dimensions of furniture prior the purchase. 
The results concerning the preferred features of senior-friendly furniture for sitting comprise an important source of inspiration when creating the product itself but also the whole communication campaign accompanying the product release. First of all, as over $80 \%$ of respondents evaluated the durability of furniture as important or very important, one should pay attention to the proper communication of this feature for example in the form of a prolonged product warranty. Such a document indicates the product is durable and the manufacturer is sure it will last for a certain period of time without failure. As much as $74 \%$ of seniors who took part in this research evaluated the stain - resistant upholstery used in the furniture as a significant functional characteristic. Furthermore, the already mentioned issue of adjusting the functional dimensions of the furniture to the anthropometrical dimensions of seniors was of paramount importance for over $60 \%$ of respondents. It is important to highlight that the authors have concentrated mainly on functional and construction features of furniture, but one should not forget that to reach to senior customers especially represented by the younger part of the baby boomer generation - namely Generation Jones, designers and producers need to take into consideration also a much wider scope of features - including aesthetic form and durability. Although these features were the most important ones despite the age group or nationality of the respondents, there were differences in the answers between different countries and age groups. As previous research suggests, the seniors perform various activities while sitting. These vary between different countries, which may have an effect on the older adults' preferences. There are also different inner decoration habits in the countries that may affect the requirements for furniture. Additional research must be conducted to further investigate the cultural aspects' effects on the detailed preferences of the seniors in different countries. The results also indicate seniors being a heterogenous group when it comes to the opinions about furniture features. To obtain more detailed explanations on the preferences of the seniors and different generations, different research methods might be useful in future studies. Providing a real experience on the different features followed by an interview may give insights. The current research does not consider the fact that people might prefer things they have or are aware of and have positive experiences on. This becomes essential especially for the generations that are modest in nature.

As far as the limitations of the study are concerned, it needs to be stated that, the theme of the design requirements is very broad and not all aspects were taken into consideration in the presented study, as they require other study methods. In the performed survey research the authors haven't been investigating for example the preferable functional dimensions. Although this is a crucial aspect when designing furniture for seniors, it is very challenging to recognize the needs concerning functional dimensions in the survey research. Thus the authors have started additional investigations taking part in the furniture testing laboratory in order to research this aspect in more detail. The subject of design requirements concerning the functional dimensions adjusted to seniors' needs will be therefore covered in future studies. Furthermore also human-related factors such as cushion and tactile sensation were not taken into consideration in the current study. Nevertheless a significant number of participants of this study allows for receiving a valuable insights into the analyzed subject. Those above listed additional factors will be investigated in further studies. 


\section{CONCLUSIONS}

1. Almost $80 \%$ of respondents preferred a high backrest reaching above the head in their armchairs. This kind of construction allows seniors to enjoy increased comfort during relaxing and gives the possibility to rest the head on the backrest while taking daily naps.

2. Over $80 \%$ of respondents evaluated the durability of furniture as important or very important feature of furniture. Thus manufacturers should not only pay their attention to provide products that will last without failure for a longer than standard 2 years lifetime but also adequately communicate the existence of this advantage for example in the form of a prolonged product warranty.

3. Over $70 \%$ of seniors from the sample population indicated that the usage of stainresistant upholstery in the furniture is a key functional characteristic. Tailoring of the functional dimensions of the furniture to the anthropometrical dimensions of seniors was important for over $60 \%$ of respondents. Therefore, the customization of furniture dimensions could be a valuable option as seniors indicated they would like to have influence, e.g., on the height and depth of the seat, before the purchase. That was especially significant for the population of women. The majority of women customers wanted to have influence on the dimensions of furniture for sitting prior the purchase: $70 \%$ on the height of the seat, $66 \%$ on the depth of the seat and $61 \%$ on the width of the seat.

4. Respondents in all studied countries presented similar preferences concerning the height of the armchair's backrest that according to their opinion should reach above the head of the user. Similarly, respondents in all countries agreed that it is easier for them to sit down and get up from furniture with armrests. When the functionality features like durability of furniture or stain-resistance material/removal upholstery are concerned the similarity of preferences among respondents in all analyzed countries is seen. That gives an important guidance on the design features that when implemented into the furniture may contribute to the market success of a given product in all analyzed Baltic Sea region countries.

5. The changes in the preferences toward the design requirements in-between the analyzed countries were seen in the case of willingness to have an armchair with the reclining/relax function. The majority of respondents in Latvia, Poland (over 60\%), and Lithuania (over 80\%) would like to have an armchair with a relax function. But in Germany, Denmark, and Finland more respondents were negative about this solution. It may be connected with the furnishing equipment of the living room and the existence in the household of a separate room dedicated for sleeping. The majority of seniors $(63 \%)$ who was not willing to have an armchair with the relaxing function had a separate room dedicated for sleeping. Further research will be performed in order to analyze this issue in more detail.

\section{ACKNOWLEDGEMENTS}

The authors are grateful that this work examined issues that constitute a part of the project: BaltSe@nioR 2.0: Innovative solutions to support BSR in providing more senior- 
friendly public spaces due to increased capacity of BSR companies and public institutions. This work was partly financed by the European Union (European Regional Development Fund and European Neighbourhood and Partnership Instrument).

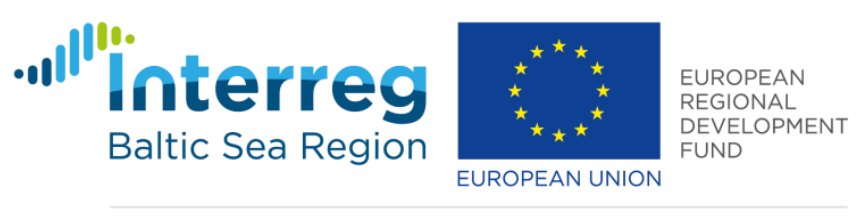

BaltSe@nioR 2.0

The authors are also grateful that this work examined issues that constitute a part of the project: BaltSe@nioR: Innovative solutions to support BSR enterprises in product development aimed at raising comfort and safety of seniors' home living. This work was partly financed by the European Union (European Regional Development Fund and European Neighbourhood and Partnership Instrument).

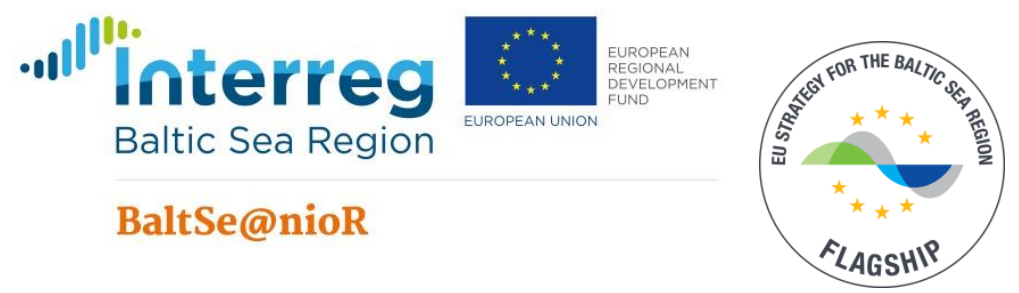

\section{REFERENCES CITED}

Baumgartner, R. N., Stauber, P. M., McHugh, D., Koehler, K. M. and Garry, P. J. (1995). "Cross-sectional age differences in body composition in persons 60+ years of age," Journals of Gerontology. Series A, Biological Sciences and Medical Sciences 50, 307-316.

Cooke, J. R., and Ancoli-Israel, S. (2011). "Normal and abnormal sleep in the elderly," Handbook of Clinical Neurology 98, 653-665. DOI: 10.1016/B978-0-444-520067.00041-1

Colombo, M., Vitali, S., Molla, G., Gioia P., and Milani, M. (1998). "The home environment modification program in the care of demented elderly: Some examples," Archives of Gerontology and Geriatrics 26(1), 83-90. DOI: 10.1016/S01674943(98)80015-0

Dey, D.K., Rothenberg, E., Sundh, V., Bosaeus, I. and Steen, B. (1999). "Height and body weight in the elderly. I. A 25 year longitudinal study of a population aged 70 to 95 years," European Journal of Clinical Nutrition 53, 905-914.

Dzięgielewski, S., and Fabisiak, B. (2005). "Forma i funkcjonalność jako czynniki determinujące jakość mebli tapicerowanych [Form and functionality as factors determining the quality of upholstered furniture]," Roczniki Akademii Rolniczej w Poznaniu CCCLXIX Technologia Drewna [Annals of the Agricultural University in Poznań CCCLXIX Wood Technology] 41, 5-17. 
European Commission (EC) (2019). Ageing Europe. Looking at the Lives of Older People in the EU: 2019 Edition, Publications Office of the European Union, Mercier, Luxembourg.

European Commission (EC) (2020a). Eurostat Regional Yearbook: 2020 Edition, Publications Office of the European Union, Mercier, Luxembourg.

European Commission (EC) (2020b). "Elderly population across EU regions," (https://ec.europa.eu/eurostat/web/products-eurostat-news/-/DDN-20200402-1), Accessed 15 Jan 2021.

European Commission (EC) (2020c). "Population structure and ageing - European Commission," (ec.europa.eu/eurostat/statistics-explained/index.php), Accessed 26 Feb 2021.

European Commission (EC) (2020d). "Population structure and ageing," (https://ec.europa.eu/eurostat/statisticsexplained/index.php/Population_structure_and_ageing\#The_share_of_elderly_people _continues_to_increase), Accessed 26 February 2021.

Fabisiak, B., and Hrovatin, J. (2014). "Preferences of Polish and Slovenian seniors concerning kitchen interior design," Annals of Warsaw University of Life Sciences SGGW Forestry and Wood Technology 86, 92-97.

Fricker, Jr., R. D. (2008). "Sampling methods for web and E-mail surveys," in: The SAGE Handbook of Online Research Methods, N. G. Fielding, R. M. Lee, and G. Blank (eds.), SAGE Publishing, Newbury Park, CA, USA, pp. 195-216.

Gavriilidou, N. N., Pihlsgård, M., and Elmståhl, S. (2015). "Anthropometric reference data for elderly Swedes and its disease-related pattern," European Journal of Clinical Nutrition 69(9), 1066-1075. DOI:10.1038/ejcn.2015.73

Gill, T. M., Williams, C. S., Robison, J. T., and Tinetti, M. E. (1999). “A populationbased study of environmental hazards in the homes of older persons," American Journal of Public Health 89(4), 553-556. DOI: 10.2105/AJPH.89.4.553

Goldman, S. E., Hall, M., Boudreau, R., Matthews, K. A., Cauley, J. A., Ancoli-Israel, S., Stone, K. L., Rubin, S. M., Satterfield, S., Simonsick, E. M., and Newman, A. B. (2008). "Association between nighttime sleep and napping in older adults," Sleep 31(5), 733-740. DOI:10.1093/sleep/31.5.733

Harvey, J. A., Chastin, S. F. M., and Skelton, D. A. (2013). "Prevalence of sedentary behavior in older adults: A systematic review," International Journal of Environmental Research and Public Health 10(12), 6645-6661. DOI: 10.3390/ijerph10126645

Harvey, J. A., Chastin, S. F. M., and Skelton, D. A. (2015). "How sedentary are older people? A systematic review of the amount of sedentary behavior," Journal of Aging Physical Activity 23(3), 471-487. DOI: 10.1123/japa.2014-0164

Jarosz, E. (1998). "Dane antropometryczne osób starszych dla potrzeb projektowania [Anthropometric data of seniors for design purposes]," Prace i Materiaty IWP [Works and Materials of the Institute of Industrial Design] 153, 1-52.

Kalka, E. (2001). "Charakterystyka somatyczna kobiet starszych w wieku 60-81 lat. Dane do projektowania odzieży [Somatic characteristic of senior women (aged 60-80). Data for clothes design]," in: VII International Scientific and Technical Conference Ergonomics for the Disabled, Łódź, Poland, pp. 1-8.

Leask, C. F., Harvey, J. A., Skelton, D. A., and Chastin, S. F. M. (2015). "Exploring the context of sedentary behaviour in older adults (what, where, why, when and with 
whom)," European Review of Aging and Physical Activity 12(1), 1-8. DOI:

10.1186/s11556-015-0146-7

Meneguci, J., Sasaki, J., Santos, A., Scatena, L., and Damião, R. (2015). “Sitting time and quality of life in older adults: A population-based study," Journal of Physical Activity and Health 12(11), 1513-1519. DOI: 10.1123/jpah.2014-0233

Østergaard, P. (1994). Fornuften i Højscedet: Mфbler for Alle [Reason in the High Seat: Furniture for All], Christian Ejlers' Forlag, Copenhagen, Denmark.

Palmer, V. J., Gray, C. M., Fitzsimons, C. F., Mutrie, N., Wyke, S., Deary, I. J., Der, G., Chastin, S. F. M., Skelton, D. A., and Seniors USP Team (2019). "What do older people do when sitting and why? Implications for decreasing sedentary behavior," The Gerontologist 59(4), 686-697. DOI: 10.1093/geront/gny020

Perissinotto, E., Pisent, C., Sergi, G., Grigoletto, F., and Enzi, G. (2002). "Anthropometric measurements in the elderly: Age and gender differences," British Journal of Nutrition 87(2), 177-186. DOI:10.1079/BJN2001487

Richert-Kaźmierska, A., and Stankiewicz, K. (2013). “Możliwość współpracy zawodowej pracowników $\mathrm{z}$ różnych grup wiekowych [Possibility of professional cooperation of employees from different age groups]," Przeglad Organizacji[Organization Review] 2(877), 15-19. DOI: 10.33141/po.2013.02.03

Richert-Kaźmierska, A. (2014). "Employees 55+ - Valuable resource in SMEs," Social Sciences 3(85), 49-57. DOI: 10.5755/j01.ss.85.3.8413

Šimek, M. (2013). “Analysis of sitting furniture for elderly people," in: Proceedings of the XXVIth International Conference Research for Furniture Industry, Poznan, Poland, pp. 78-82.

Sullivan, L. H. (1896). "The tall office building artistically considered," Lippincott's Magazine, 339 (March), 403-409.

Timlin, G., and Rysenbry, N. (2010). Design for Dementia: Improving Dining and Bedroom Environments in Care Homes, Helen Hamlyn Centre, Royal College of Art, London, UK.

Tinietti, M. E., Baker, D. I., Mcavay, G., Claus, E. B., Garrett, P., Gottschalk, M., Koch, M. L., Trainor, K., and Horwitz, R. I. (1994). "A multifactorial intervention to reduce the risk of falling among elderly people living in the community," New England Journal of Medicine 331(13), 821-827. DOI: 10.1056/NEJM199409293311301

Ugolini, F., Massetti, L., Calaza-Martínez, P., Cariñanos, P., Dobbs, C., Krajter Ostoić, S., Marin, A. M., Pearlmutter, D., Saaroni, H., Šaulienè, I., et al. (2020). "Effects of the COVID-19 pandemic on the use and perceptions of urban green space: An international exploratory study," Urban Forestry \& Urban Greening 56, Article ID 126888. DOI: $10.1016 /$ j.ufug.2020.126888

World Health Organization (WHO) (2021). "World health data platform," (https://www.who.int/data/gho/indicator-metadata-registry/imr-details/116), Accessed 03 Feb 2021.

Xin, C., Zhang, B., Fang, S. and Zhou, J. (2020). "Daytime napping and successful aging among older adults in China: A cross-sectional study," BMC Geriatrics 20, 2. DOI:10.1186/s12877-019-1408-4

Article submitted: March 2, 2021; Peer review completed: May 8, 2021; Revised version received and accepted: July 14, 2021; Published: July 26, 2021.

DOI: 10.15376/biores.16.3.6244-6266 